\title{
Risk of several psychiatric disorders was increased in relatives of anorexics and bulimics
}

\author{
Lilenfeld LR, Kaye WH, Greeno CG, et al. A controlled family study of anorexia nervosa and bulimia nervosa. Psychiatric disorders \\ in first-degree relatives and effects of proband comorbidity. Arch Gen Psychiatry 1998 Jul;55:603-10.
}

\section{Question}

In patients with anorexia nervosa or bulimia nervosa what are the familial patterns of psychiatric disorders?

\section{Design \\ Case control study.}

\section{Setting}

Inpatient and outpatient eating disorder programmes at Western Psychiatric Institute and Clinic, Pittsburgh, Pennsylvania, USA.

\section{Participants}

26 women (mean age 25 y) with DSM-III-R criteria for anorexia nervosa (including 93 relatives), 47 women (mean age $25 \mathrm{y}$ ) with $D S M-I I I-R$ criteria for bulimia nervosa (including 177 relatives), and 44 women (mean age $26 \mathrm{y}$ ) with no history of an eating disorder (including 190 relatives). Controls were matched by age and postal code to cases.

\section{Assessment of risk factors}

Lifetime prevalence rates of eating disorders (Eating Disorders Family History Interview), mood disorders, substance use disorders, anxiety disorders (Schedule for Affective Disorders and Schizophrenia-Lifetime Version [or the school age version for those $<18$ years of age]), and selected personality disorders (Structured Clinical Interview for DSM-III-R Personality Disorders, and the Personality Disorders Examination) were determined using face to face interviews or by telephone. Interviewers were blinded to the identity of the families.

\section{Main outcome measure}

Risk of disorders among first degree relatives.

\section{Main results}

After adjustment for sex, age, and interview type, relatives of patients with anorexia and bulimia had increased risk of major depressive disorder, clinically subthreshold forms of an eating disorder, generalised anxiety disorder, and obsessive-compulsive disorder (table). The risk of substance dependence was reduced among relatives of patients with anorexia compared with relatives of patients with bulimia (risk ratio [RR] 0.5, 95\% CI 0.3 to 1.0), and familial aggregation was independent of bulimia. The risk of obsessive-compulsive personality disorder was increased only among relatives of patients with anorexia (RR 3.6, CI 1.6 to 8.0), and evidence existed that these 2 disorders may have shared familial risk factors. Both major depression and obsessive-compulsive disorder appeared to be transmitted independently from eating disorders.

\section{Conclusion}

Risk of major depression disorder, subthreshold eating disorders, generalised anxiety disorder, and obsessive-compulsive disorder was increased in first degree relatives of patients with anorexia nervosa or bulimia nervosa compared with patients without these disorders.

Adjusted risk ratios (95\% CI) for disorders among first degree relatives of patients with eating disorders and those without

\begin{tabular}{lll}
\hline $\begin{array}{l}\text { Disorder } \\
\text { Major depressive }\end{array}$ & Anorexia v control women & Bulimic v control women \\
$\begin{array}{l}\text { disorder } \\
\begin{array}{l}\text { Eating disorder, not } \\
\text { otherwise specified }\end{array}\end{array}$ & $2.3(1.1$ to 4.8$)$ & $2.3(1.2$ to 4.4$)$ \\
$\begin{array}{l}\text { Generalised anxiety } \\
\text { disorder }\end{array}$ & $3.1(1.5$ to 6.8$)$ & $30.7(4.1$ to 228.0$)$ \\
$\begin{array}{l}\text { Obsessive-compulsive } \\
\text { disorder }\end{array}$ & $4.1(1.4$ to 12.2$)$ & $2.3(1.1$ to 4.7$)$ \\
&
\end{tabular}

Source of funding: National Institute on Alcohol Abuse and Alcoholism

For correspondence:Dr WH Kave, Department of Psychiatry, University of Pittsburgh Medical Center, 3811 O'Hara Street, Pittsburgh, PA 15213-2593, USA. Fax +1 4126246618.

\section{Commentary}

This study represents an important advance in the study of the heritability of eating disorders. It was carefully designed and the analytical approach is state of the art.

The key findings relate to which disorders might have shared genetic vulnerabilities. Despite controversy over the exact association between anorexia nervosa and bulimia nervosa, only a few attempts have been made to sort out whether they share genetic vulnerabilities or are inherited as separate conditions. Previous work in this area has been ambiguous or suggested separate inheritance. $^{1-4}$

Investigation of the co-inheritance of other psychiatric disorders and eating disorders is one strategy to investigate this, and it is of interest given the high rates of familial occurrence in individuals with anorexia nervosa and bulimia nervosa. This study confirms other work suggesting separate transmission for major depression and substance use, and adds obsessive-compulsive disorder to this list. Of interest, however, is the finding that obsessive-compulsive personality disorder (OCPD) may share some genetic risk factors with anorexia nervosa, and in fact may be a risk factor for its development.

Such findings may have clinical relevance that could eventually lead to the development of strategies for identifying individuals at risk of developing eating disorders, at whom preventative strategies could be more efficiently targeted. In addition, this will have implications for treatment programmes, for example sug- gesting an aggressive therapeutic approach to the treatment of OCPD in those recovering from anorexia nervosa. Such a strategy would emphasise the need for an integrative approach to the treatment of eating disorders-one which requires an understanding of the biology and psychology of the illnesses.

\section{Blake Woodside, MD, FRCPC The Toronto Hospital Toronto, Ontario, Canada}

1 Strober M. I Psychosom Res 1980;24:353-59.

2 Strober M, Lampert C, Morrell W, et al. Int J Eat Strober M, Lampert C,
Disord 1990;9:239-53.

Disord 1990:9:239-53. Strober M. Substance abuse disorder and bulimia nervosa: familial vulnerability. Presented at the International Conference on Eating Disorders; April 27, 1995; New York, NY.

4 Woodside DB, Field LL, Garfinkel PE, et al. Comp Psychiatry 1998;39:261-4. 